\title{
The identification of wildlife-vehicle collision hotspots: Citizen science reveals spatial and temporal patterns
}

\author{
Francesco Valerio ${ }^{1,2,3+}$, Marco Basile ${ }^{3,4^{*}+}$ (D) and Rosario Balestrieri ${ }^{3,5}$
}

\begin{abstract}
Linear infrastructures (e.g., roads, railways, pipelines, and powerlines) pose a serious threat to wildlife, due to the risk of wildlife-vehicle collisions (roadkills). The placement of mitigation measures, such as crossing structures, should consider species' life cycles and ecological requirements. Such an assessment would require data collection over large areas, which may be possible by employing citizen science. In this study, we aimed to identify spatiotemporal trends of roadkill occurrence using citizen science data from one of the most urbanized and biodiversityrich regions of Italy. Temporal trends were analyzed using generalized additive models, while landscape patterns were assessed by identifying significant thresholds over land cover gradients, related to increases in relative roadkill abundance, by employing threshold indicator taxa analysis. Our approach recorded a total of 529 roadkills, including 33 different species, comprising 13 mammal, 10 bird, 6 reptile, and 2 amphibian species. Statistical analysis indicated significant temporal trends for the red fox, the European hedgehog, the stone marten and the European badger, with peaks in roadkill occurrence between the winter and spring months. Relative roadkill abundance increased mostly in landscapes with anthropogenic land cover classes, such as complex cultivations, orchards, or urban surfaces. Our results allowed us to develop a map of potential roadkill risk that could assist in planning the placement of mitigation measures. Citizen science contributions from highly populated areas allowed data collection over a large area and a dense road network, and also directly led to the evaluation of management decisional options.
\end{abstract}

Keywords: Roadkill, Land cover, Road ecology, Seasonal trend, Spatial prioritization, Urban wildlife

\section{Background}

The rapid growth of human population is fostering the development of linear infrastructures worldwide, heightening concerns about the anthropogenic pressure on the Earth's environment and habitats (Haddad 2015; Laurance et al. 2015; van der Ree et al. 2015). Road infrastructure threatens biodiversity both directly, by physically bisecting

\footnotetext{
* Correspondence: marcob.nat@gmail.com

Francesco Valerio and Marco Basile are co-primary authors.

${ }^{\dagger}$ Francesco Valerio and Marco Basile contributed equally to this work.

${ }^{3}$ Associazione per la Ricerca, la Divulgazione e l'Educazione Ambientale -

ARDEA, Via Ventilabro, 80126 Napoli, Italy

${ }^{4}$ Chair of Wildlife Ecology and Management, University of Freiburg,

Tennenbacher Str. 4, 79106 Freiburg, Germany

Full list of author information is available at the end of the article
}

landscapes, thus reducing and fragmenting habitats on their way, and indirectly, by degrading landscape quality (Saunders et al. 2002; Coffin 2007; Bennett 2017). Such consequences may also have a strong adverse effect on wildlife by hampering population viability, thus leading to possible local extinctions (Benítez-López et al. 2010; van der Ree et al. 2011). Globally, one of the most important direct and detrimental impacts on wildlife is the collision with vehicles while crossing roads (Forman and Alexander 1998; Bennett 2017), which may result in millions of collisions per year globally (Nyhus 2016). This in turn sparks human-wildlife conflicts driven by compromised road safety: for example, deer-vehicle collisions are estimated at $\sim 2$ million/year in Europe and the USA, with more than 
200 human deaths/year and another 30,000 injuries, while other estimates indicate that 194 million birds and 29 million mammals are killed on European roads every year (Bissonette et al. 2008; Langbein et al. 2011; Grilo et al. 2020). In this sense, road mitigation measures are a crucial tool to limit wildlife-vehicle collisions (roadkills) and to guarantee safety for wildlife and humans (van der Grift and van der Ree 2015). When taking into account the alarming expansion of the road network expected in the near future, the management of road infrastructures to halt roadkills is likely to become a topical issue in conservation and landscape planning (Meijer et al. 2018).

A paramount aspect when aiming to reduce risks for wildlife from road infrastructure lies in the efficient identification of crossing sites, whose location may in turn vary depending on habitat types and landscape characteristics surrounding the road segments (Červinka et al. 2015; Russo et al. 2020). This is mainly because landscape elements may be key drivers of roadkills (Mimet et al. 2016; Tanner et al. 2017; Valerio et al. 2019). Hence, particularly for landscapes incorporating several habitat types, the habitat composition of a given landscape should be considered when addressing the drivers of roadkill occurrence; this is a fundamental aspect for practitioners aiming at spatially prioritizing the placement of road-crossing structures, in order to facilitate wildlife movements and mitigate animal road mortality (Grilo et al. 2011; Mimet et al. 2016; Valerio et al. 2019).

Efficient mitigation measures usually take into account species ecological requirements, such as home range sizes and habitat preferences (Grilo et al. 2016). Another important aspect for guiding mitigation measures concerns the identification of temporal trends in roadkills, which often occur during particular periods depending on the specific life histories of individual species (Grilo et al. 2009). However, despite the relatively easy accessibility of road casualties, the cost of monitoring roads usually faces steep increases due to the intensive survey effort required, including daily surveys to avoid uncertainty (Santos et al., 2011).

To overcome the cost of roadkill surveys over large areas, one possible solution is to implement citizen science strategies to collect data. Such an approach has been successfully applied to the case of single, rare species, whenever survey costs faced increases due to the infrequency of collisions (Dwyer et al. 2016). Smartphone applications, systems for data storage, and web applications for data visualization have further facilitated citizens' involvement (Olson et al. 2014). Citizen science contributions can allow researchers to monitor and model roadkill occurrence across tertiary, often remote roads, and even cycling paths (Heigl et al. 2017). While the use of data collected by citizens has intrinsic costbenefit advantages, these, however, might be disguised by the disadvantages. Species misdetection and/or misidentification, for example, are a potential source of bias (Santos et al. 2011), especially when dealing with taxa less known to the general public (Vantieghem et al. 2017). Temporal clustering should also be addressed, considering that citizen science data might have an appreciable degree of temporal correlation (Bird et al. 2014). On the other hand, strategies to cope with data quality have been developed and included a plethora of solutions, ranging from early actions that take place prior data collection (e.g., training), to field actions (e.g., technological aids) as well as office actions (e.g., validation of observations) (Freitag et al. 2016). The validation step is particularly important in the case of opportunistically collected data as it may reduce data autocorrelation via data filtering procedures (Vercayie and Herremans 2015).

By employing a citizen science approach and carefully considering its possible shortcomings, we collected a large data set on roadkills in Campania, one of Italy's most densely populated regions. The main objectives of the study were to identify (1) species more likely to be subject to vehicle collisions, thus assessing the occurrence of roadkills over the study area, (2) whether species mortality trends were limited over specific times of the year, and (3) whether roadkill relative abundance increases with particular habitat types. We developed a series of data collection tools and strategies to facilitate citizens' involvement and to allow us to cover a large area, ranging from densely urbanized cities, including Italy's third-largest city, to remote mountains. Our approach did not limit data collection to focal species, but rather identified them based on abundance of collisions. Ultimately, we aimed to show that a spatio-temporal assessment of roadkill risk for multiple species across road networks can make use of citizen science in densely populated areas and identify road sections of greater cumulated risk, i.e., best locations for mitigation measures.

\section{Methods}

\section{Study area}

The study was limited to the road network of the Campania Region, one of the 20 administrative regions of Italy (Fig. 1). The region covers $\sim 13,600 \mathrm{~km}^{2}$ and is located in the Mediterranean biome. The elevation spans from sea level to almost $2000 \mathrm{~m}$ a.s.l. and is characterized by several rainfall regimes (annual precipitation 700$800 \mathrm{~mm}$ on the coastline, while up to $1800 \mathrm{~mm}$ on mountain ranges; Ducci and Tranfaglia 2008), as well as mean temperatures spanning from $\sim 10^{\circ} \mathrm{C}$ on the mountains to $\sim 18{ }^{\circ} \mathrm{C}$ on the coast; Ducci and Tranfaglia 2008). The mountainous Apennine carbonate chain constitutes the majority of the region's landlocked area, transitioning to hills and lowlands when it approaches to 


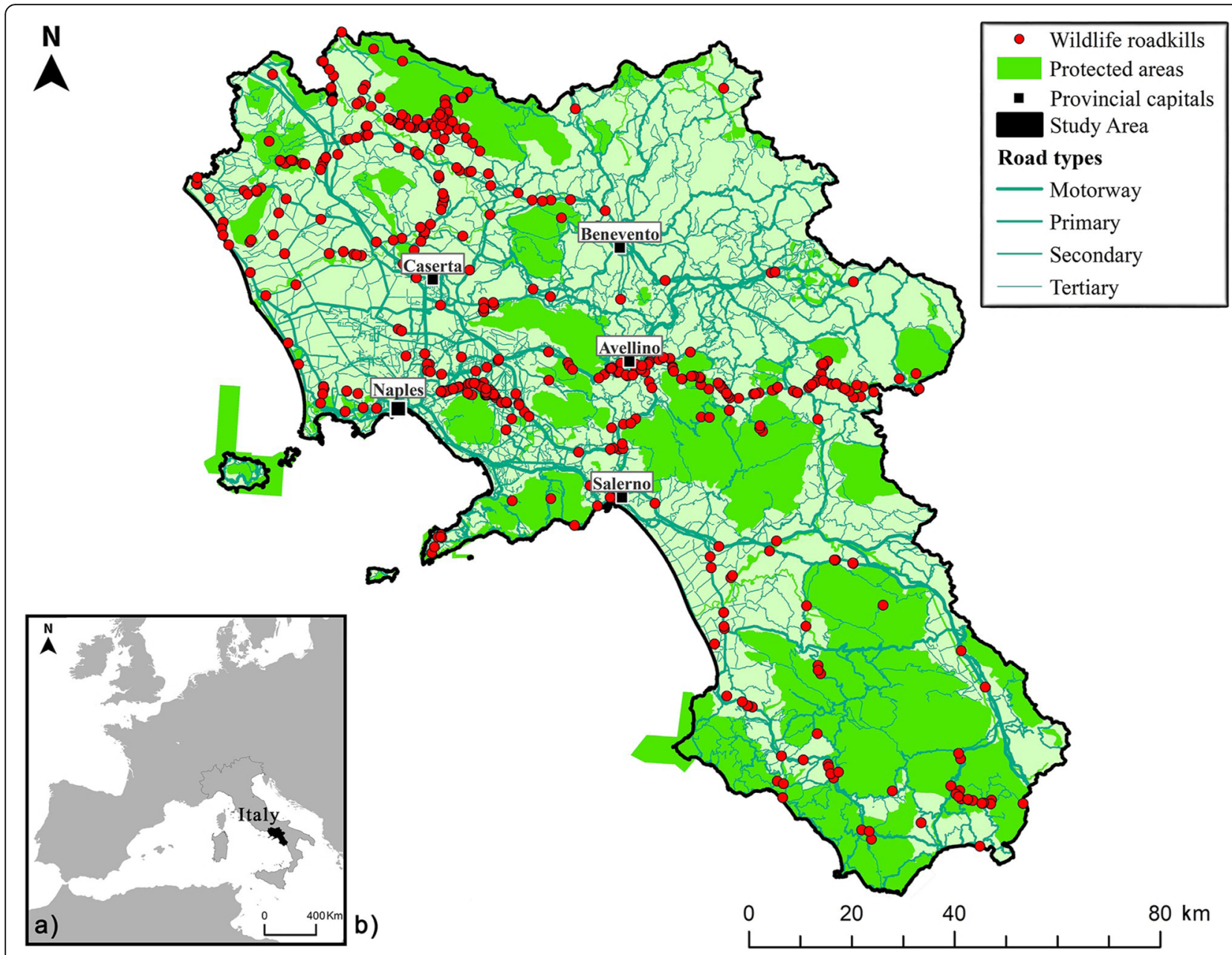

Fig. 1 Location of study area. (a) Campania Region in south Italy and (b) roadkill locations with protected areas, provincial capitals, and type of roads

the (partly) volcanic coastline. Due to its geography, the gradient in altitude from the coast to the interior is mirrored by the gradient in urbanization and road network development (Fig. 1b). In the hilly lowland part, farmland is a frequent land cover class (55\% of covered area), followed by natural and non-natural forests ( 37\% of covered area), which are mostly located at higher altitudes. Human activities, however, have proven to be a major driver of land-use change in the last decades, primarily associated with urban expansion (Migliozzi et al. 2010). Indeed, Campania is one of the most populated regions of Italy $(\sim 5,800,000$ inhabitants; source: demo.istat.it), characterized by artificial surfaces representing $\sim 8 \%$ of the territory, a remarkable road network $\sim 11000 \mathrm{~km}$ long, with an average road density of $\sim 0.8$ $\mathrm{km} / \mathrm{km}^{2}$. The gradient in urban development resulted in Napoli Metropolitan City along the coast having a road network double in length than the landlocked province of Benevento, though the area covered by the latter is approximately two times larger $\left(1.171 \mathrm{~km}^{2}\right.$ vs. $2.080 \mathrm{~km}^{2}$, respectively). Conversely, Campania also includes a number of protected areas, including two national and ten regional parks, representing $\sim 27 \%$ of the territory.

\section{Citizen data collection}

Data collection was designed to be carried out by citizens coming across wildlife-vehicle impacts via a supervised data collection system, which allowed us to cover the entire region, both in the proximity of densely populated areas as well as in less populated ones such as protected or mountainous areas (Fig. 1b). It included the participation of expert surveyors, web aid, open-access software such as Google Earth, and smartphone applications, followed a data validation procedure (Fig. 2). Skilled surveyors facilitated the involvement of less experienced citizens and constituted the first batch of surveyors. Some of them participated in training sessions, where either identification skills or the data collection 


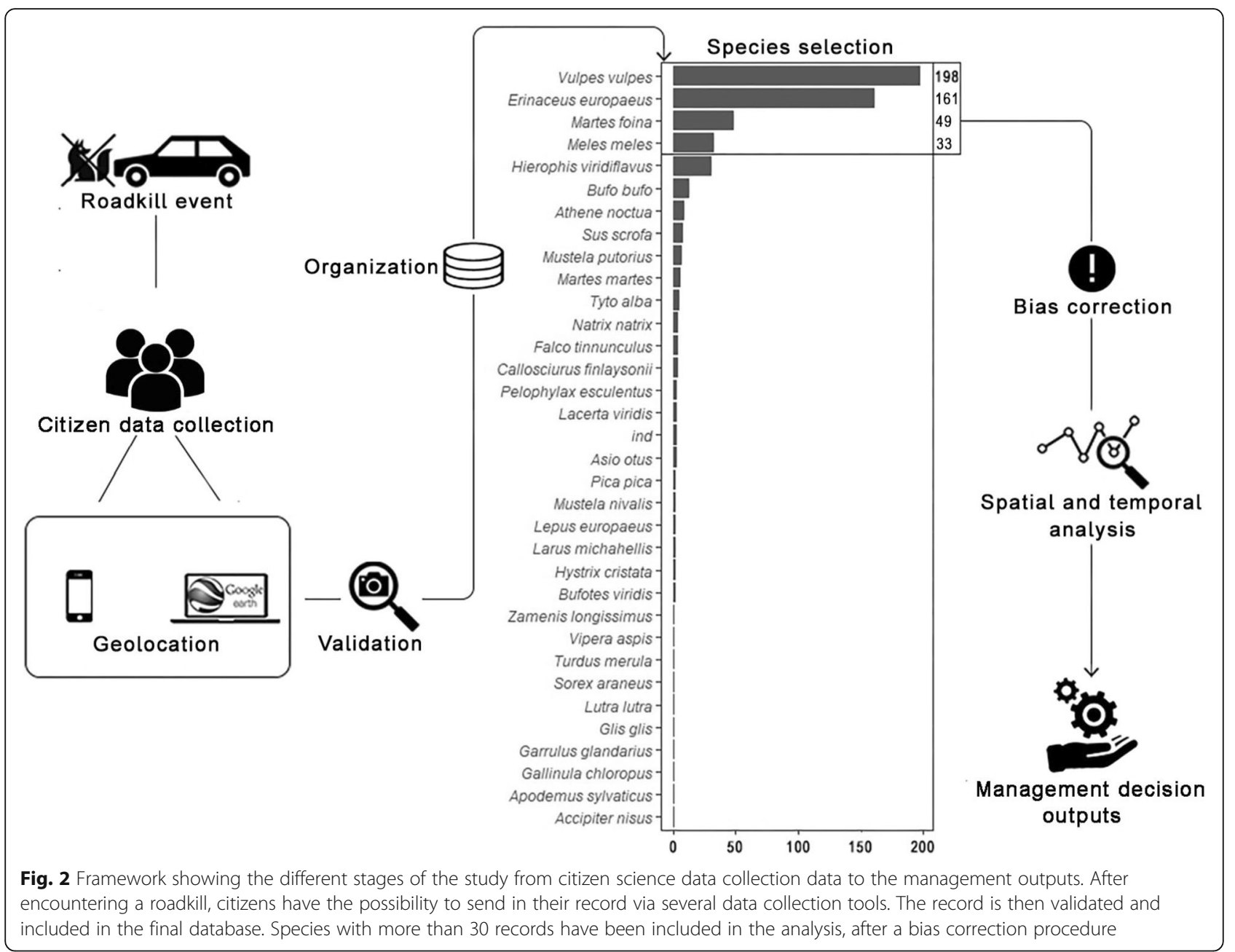

systems were the main subject. This early phase was continuously advised by scientists. Thereafter, in the data collection phase, a plethora of options for data transfer were made available to the surveyors, who were free to choose the method. The most common was the use of direct message apps, such as WhatsApp, which has the advantage of being extremely fast, while also making it possible to attach photographic documentation of the roadkill and a GPS location. Other methods included the possibility to send data via web app, such as Google Maps, or GPS positions collected with standard GPS devices. The choice of the data transfer option was designed to impact as little as possible the safety of the surveyors. Citizens' data spanned from 01 August 2014 to 31 October 2016. In addition, observations of animals crossing the road were also accepted. Further records dating back up to 2004 were retrieved from expert surveyor notes.

\section{Scientist data validation and correction}

The data were included in the database after a validation procedure conducted by scientists. Firstly, photographic records from participants, attached with the relevant data, which was compulsory for less skilled surveyors, were inspected to validate the species. Thereby, a temporal rarefaction procedure was carried out to account for potential double counts. Carcasses were rarely collected during road cleaning efforts and were usually left on the road for a considerable amount of time. Species occurrences at road segments were filtered by considering as double counts any records reported over a time span shorter than the carcass persistence time of that particular species, calculated on the basis of each species' body weight (Santos et al. 2016). This procedure-leveled unbalances in data reporting across volunteers, since those driving more frequently had fewer chances to retain temporally close data in the final dataset. Spatial uncertainty of roadkill locations was accounted for by assuming a potential error of less than $500 \mathrm{~m}$ (corresponding to the minimum unit of road segment size; see below for further details) in both road directions from the recorded carcass position. This accounted for GPS imprecision and for the "walking dead" phenomenon that may happen when carcasses are dragged by cars or 
scavengers (Santos et al. 2011). Finally, species with a sample size $n \geq 30$ were included in the statistical analysis.

\section{Predictor variables}

The environment, and more specifically landscape composition, was described using land cover data, retrieved from the CORINE Land Cover classification (CLC 2012; https://land.copernicus.eu/pan-european/corine-landcover/clc-2012). The CLC is based on a nominal scale of $1: 100,000$, an array of classes divided into three hierarchal levels of organization and a resolution of $100 \mathrm{~m}$. Third-level classes underwent an expert-based reclassification, aimed at decreasing the number of classes from 44 to 16 (Table S1), in order to avoid model overparameterization. The road network (OpenStreetMap 2019), was divided in road segments of $500 \mathrm{~m}$ and 1000 $\mathrm{m}$, over which we applied on both sides a buffer of 500 $\mathrm{m}$ and $1000 \mathrm{~m}$, respectively, with a flat end option in the QGIS software v3.0. Then, the share of land covered by each land cover class was quantified in the buffer area surrounding road segments, in order to obtain a gradient for each land cover class and road segment length. Buffer extents were chosen to account for uncertainty around crossing sites (Červinka et al. 2015; Valerio et al. 2019), and the trade-off between identifying hotspots and covering a large area, which is shown to be most effective at a scale between 200 and $2000 \mathrm{~m}$ (Spanowicz et al. 2020).

\section{Predicting wildlife-vehicle collisions over time and space Temporal analysis}

Temporal trends in roadkill occurrence were analyzed with Generalized Additive Models, i.e., GAM (Hastie and Tibshirani 1990). Specifically, a flexible GAM variant, PROC GAM (Xiang 2001) was employed, given its capacity for dealing with data fluctuation and for highlighting general trends, as well as for relaxing the assumption of linearity between dependent and explanatory variables (Xiang 2001). Roadkill monthly number was the response variable and months were expressed as a smoothing component. Since the response variable consisted of counts, a Poisson regression with a log link was applied. The PROC GAM algorithm was computed in the SAS software (Khattre and Naik 2018). PROC GAM ran with default parameters and underwent a generalized cross-validation (Hutchinson and de Hoog 1985). Advantages of this method lie in the associated good performance (Thompson et al. 1991) and efficient computational time, as well as an automatic selection of the smoothing parameter (Ramsay and Silverman 2005) which in turn helps the model minimize the prediction error as well as overfitting (Wahba 1990). PROC GAM incorporates the chi-square statistic, which was used to test the hypothesis of no seasonal trend on each selected species.

\section{Landscape thresholds}

The influence of landscape composition on roadkill occurrence was investigated by employing a Threshold Indicator Taxa Analysis (TITAN). This approach, which aims to identify the thresholds along landscape gradients where a species' relative abundance increases (i.e., roadkill abundance), uses change-point analysis and indicator species analysis (Baker and King 2010). Change-points are non-linear responses in abundance of a species along an environmental gradient. The indicator species analysis, on the other hand, is an unbiased measure of abundance which employs IndVal scores (Dufrêne and Legendre 1997). Hence, this approach allows to identify species that increase or decrease their abundance with increasing landscape gradient. We carried out TITAN analysis using the $\mathrm{R}$ package TITAN2 and default settings (Baker and King 2010). The analysis was performed for every land cover class gradient and for the target species, whose home range sizes approach the scale at which the landscape has been described (Travaini et al. 1993; Rosalino et al. 2004; Carvalho and Mira 2011). The analysis was performed for both road segment lengths considered in this study. Two diagnostic indices provided by TITAN were used to assess the credibility of the change-points, purity, and reliability, both set at the level of 0.9. Since we performed a TITAN analysis on roadkills, the "positive" response in abundance refers to increase in roadkills. The response of each species along each land cover class gradient was translated into a binary response, where all the road segments showing a gradient above the lower confidence interval threshold were assigned a value of 1 . Then, the binary responses of each species were summed up to produce the final map of collision risk. The procedure was repeated for both considered road segment length.

\section{Results \\ Citizen science data}

Our citizen science data collection returned a total of 529 records, including 33 different species (Fig. 2), comprising 13 mammal, 10 bird, 6 reptile, and 2 amphibian species. The most common species in the database (Table 1), following data validation and correction, were the red fox (Vulpes vulpes; 186 records), the European hedgehog (Erinacaeus europaeus; 152 records), the stone marten (Martes foina; 44), and the European badger (Meles meles; 33), all of which were then included in the statistical analysis. On average, we reported 14.5 roadkills/month $( \pm 20 \mathrm{SD})$. The greatest share of roadkills was reported on secondary roads, accounting for $60 \%$ of the total. Roadkills were more frequently reported during March-July, where they accounted for $60 \%$ of the total roadkill. The participation of citizens reached its peak at 36 surveyors involved over 
Table 1 Rarefied monthly count of roadkills for the total number of species recorded and the four most abundant species

\begin{tabular}{|c|c|c|c|c|c|}
\hline Month & Total & Red fox & Eurasian hedgehog & Stone marten & European badger \\
\hline January & 48 & 29 & 8 & 2 & 2 \\
\hline February & 29 & 20 & 3 & 2 & 3 \\
\hline March & 71 & 28 & 25 & 2 & 0 \\
\hline April & 92 & 28 & 31 & 19 & 3 \\
\hline May & 71 & 19 & 24 & 5 & 4 \\
\hline June & 43 & 14 & 14 & 4 & 2 \\
\hline July & 54 & 18 & 17 & 2 & 4 \\
\hline August & 15 & 0 & 5 & 0 & 0 \\
\hline September & 16 & 5 & 1 & 2 & 0 \\
\hline October & 22 & 3 & 3 & 1 & 3 \\
\hline November & 20 & 7 & 3 & 3 & 2 \\
\hline December & 48 & 15 & 18 & 2 & 10 \\
\hline
\end{tabular}

3 years. Each citizen transferred on average 8.6 records ( \pm 13.9 SD), with one citizen sending up to 120 records.

\section{Temporal analysis}

The monthly effect on wildlife roadkill abundance was found to be significant and noticeable for the red fox, the European hedgehog, and the stone marten $(p<$ 0.0001), while the evidence for seasonality in the records of the European badger was less pronounced $(p=0.0291)$ (Table 2; see Table S2 for further details regarding PROC GAM results). Temporal trends were smoother for the red fox, the European hedgehog, and the stone marten, while the European badger trends showed greater uncertainty (Fig. 3). Estimated trends were similar across species, with roadkills increasing at the end of winter, in particular reaching a peak around early spring for red fox, stone marten, and European hedgehog. Trends steeply decreased during late spring-summer (May/June-August/September) for all species.

\section{Landscape thresholds}

The TITAN analysis revealed threshold responses for 9 out of 14 land cover classes. Positive responses emerged for 5 land cover classes at both road segment lengths (Fig. 4). The most common land cover classes with significant change points were complex cultivation, orchard, and urban habitats. Along the gradients of these classes, the European badger, the red fox, and the European hedgehog showed significant change points. The analyses that employed the smaller road segment length, however, returned wider confidence intervals and less precise estimates. The European badger showed similar responses for the two road segment lengths, but the confidence interval was narrower for the longest length. Negative responses also emerged for four land cover classes. In particular, complex cultivation, cultivation, and olive groves returned significant change points for stone marten, red fox, and European hedgehog at the road segment length of $1000 \mathrm{~m}$ (Fig. 5), while at the smaller length, only red fox and European hedgehog had significant change points across cultivations, olive groves, and forests.

Lastly, a risk assessment map was produced for the entire Campania Region from the results relative to the road segment length of $1000 \mathrm{~m}$, given the higher precision of the estimates (Fig. 6). The geographical output showed that overall, across the region, there is a medium level of collision risk for wildlife, with higher risk areas close to mountain ranges and protected areas, in the proximity of large cities, and across large agricultural areas.

Table 2 Model parameters from the GAM. The regression and the smoothing model analysis are performed for the variable "month." The full outcome of the GAMs is reported in Table S2

\begin{tabular}{|c|c|c|c|c|c|c|}
\hline \multirow[t]{2}{*}{ Species } & \multicolumn{3}{|l|}{ Regression } & \multicolumn{3}{|c|}{ Smoothing } \\
\hline & Month & $t$ value & $p$ & Month & Chi-square & $p$ \\
\hline Red fox & $-0.13(0.02)$ & -5.94 & $<0.01$ & 0.72 & 23.81 & $<0.01$ \\
\hline European hedgehog & $-0.07(0.03)$ & -2.67 & 0.03 & 0.7 & 70.89 & $<0.01$ \\
\hline Stone marten & $-0.1(0.05)$ & -2.03 & 0.13 & 0.16 & 33.56 & $<0.01$ \\
\hline European badger & $0.11(0.05)$ & 2.35 & 0.09 & 0.19 & 11.69 & 0.03 \\
\hline
\end{tabular}



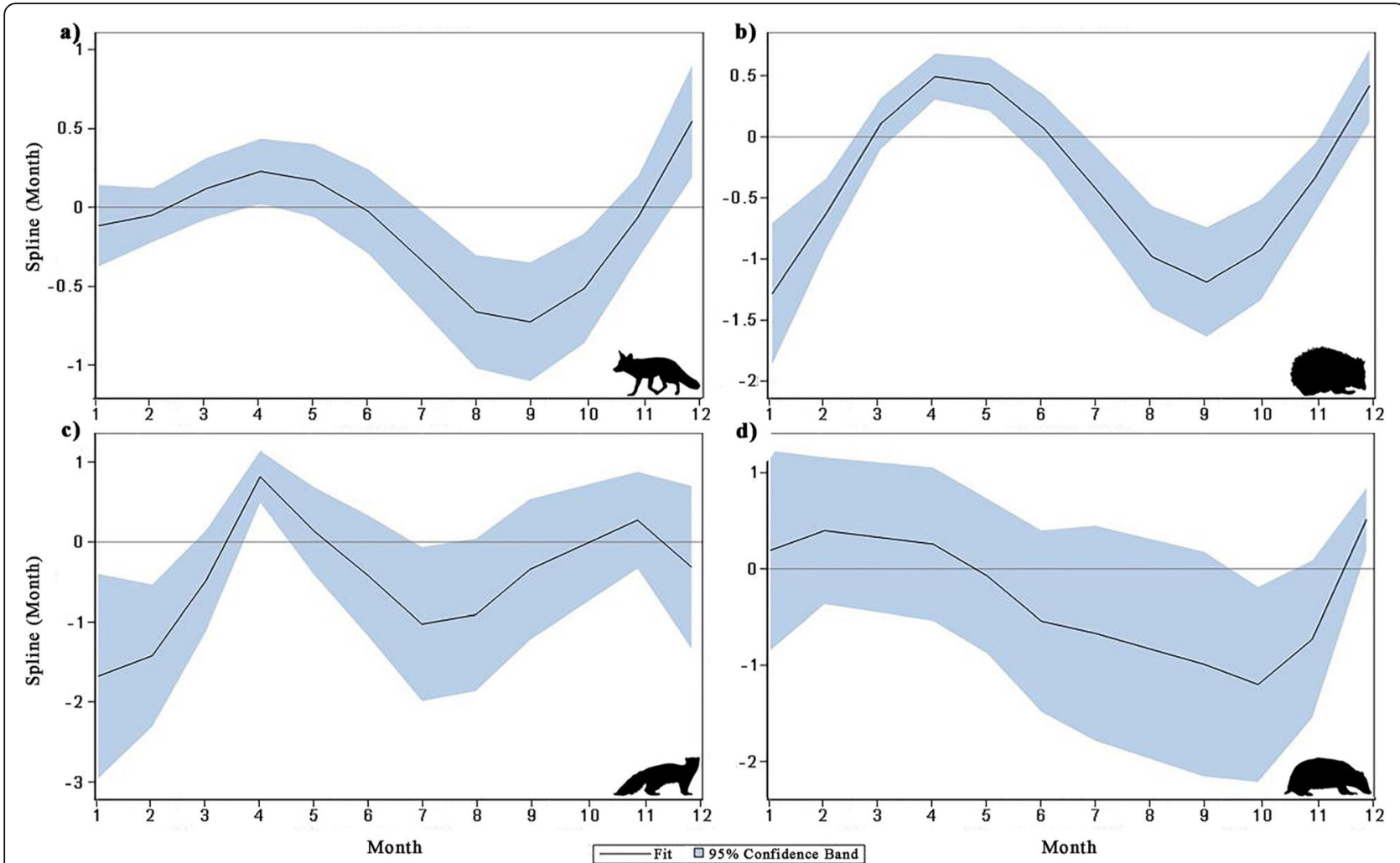

Fig. 3 Predicted roadkill temporal trends with 95\% confidence intervals of the smoothing model component (month) using Generalized Additive Models (PROC GAM) for red fox (a), European hedgehog (b), stone marten (c), and European badger (d)

\section{Discussion}

\section{Temporal trends}

Roadkill occurrence for the selected species showed a distinct seasonality, confirming that roadkill seasonal patterns may be detectable from citizen science data (Vercayie and Herremans 2015). The results for the red fox showed a protracted increase in mortality through the beginning of the spring. Such trends have been reported for urbanized areas, in particular with increases observed during summer months (Baker et al. 2007). During spring months, instead, non-reproductive female foxes tend to show large home range sizes in less suitable territories, which can likely result in an increased collision probability over this period (Henry et al. 2005). Similar mortality trends were observed for the stone marten (Grilo et al. 2013), which also shows a different daily activity pattern during spring months, when it increases diurnal activity (Posillico et al. 1995), hence when road traffic is expected to be more intense. In Italy, this period comes in early spring, but, across a species' geographic range, it may shift (Grilo et al. 2009). For instance, more stone marten roadkills were found in summer rather than in spring in Bulgaria (Raichev 2014). It is therefore of pivotal importance to consider geographic variation in species life cycles, an aspect poorly addressed that deserves further research work across species' geographical ranges. Regarding the European hedgehog's movements, another mechanism that might drive mortality may be spring movements related to the breeding period (Haigh et al. 2014). This is also observed for closely related species, where the search for a mate results in seasonal higher density of individuals (Abu Baker et al. 2017). The European badger tends to move more during summer months, especially in more patchy territories and in primeval forests (Kowalczyk et al. 2006). Indeed, in heterogeneous landscapes, a difference in movement patterns has been observed over the seasons, which is likely linked with the climatic conditions and the use of dens and latrines (Rogers et al. 1998; Noonan et al. 2014). It should be remarked that the European badger was represented by the smallest dataset in our analysis, which might have affected the confidence of our results.

\section{Landscape effect on roadkills}

The most common land cover class for increasing abundance of roadkills was orchards, followed by complex cultivation. It is worth noting that uncertainty about environmental thresholds along land cover gradients decreased at the scale of 1000, given the narrower 


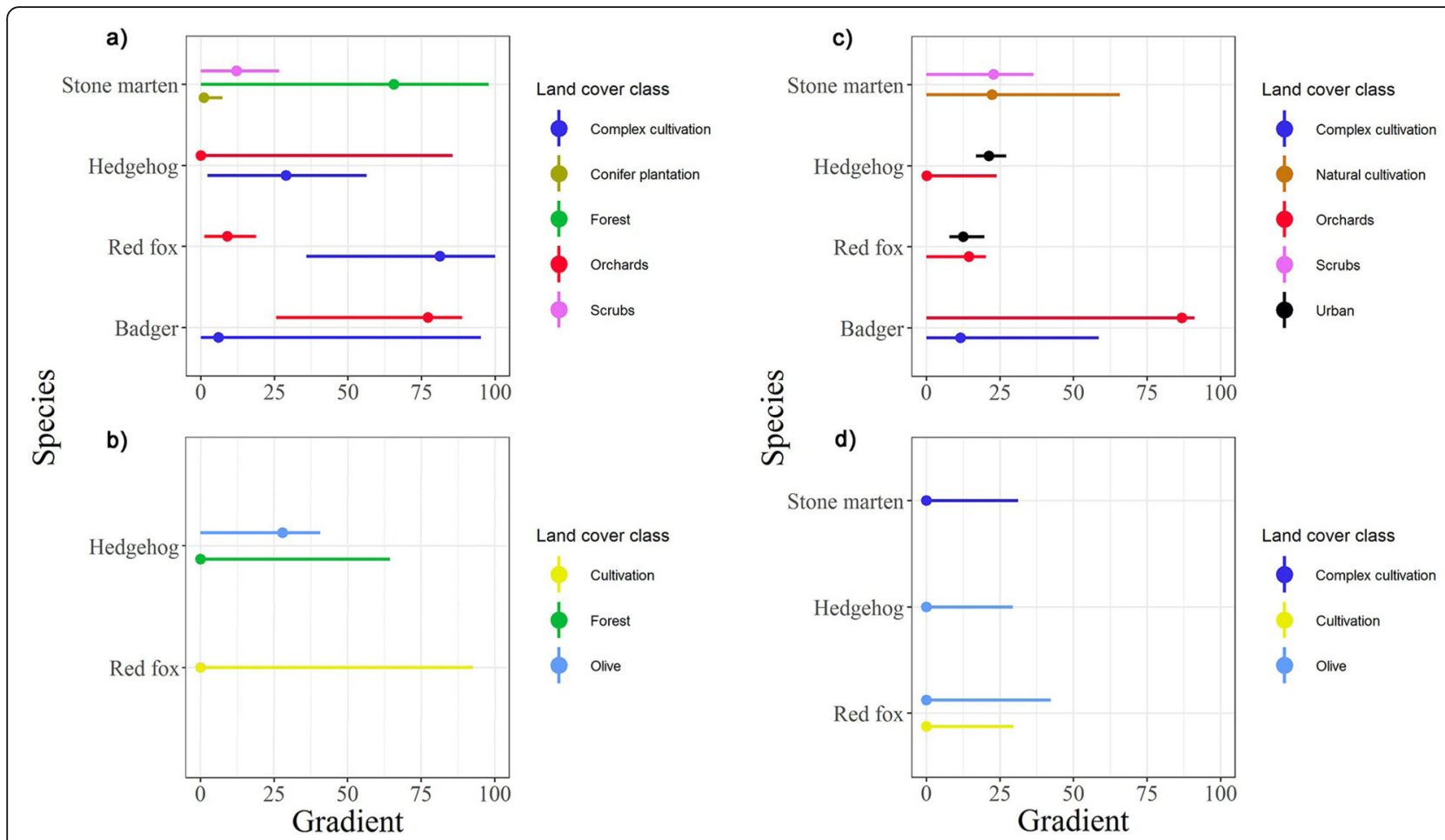

Fig. 4 Change-points, with 95\% confidence interval, for each species along the respective land cover gradient. Positive (a, c) and negative (b, d) change points are shown for road segment lengths of $500 \mathrm{~m}$ and $1000 \mathrm{~m}(\mathbf{a}, \mathbf{b}$ and $\mathbf{c}, \mathbf{d}$, respectively)

confidence intervals, corroborating such spatial scale extent as adequate for meso-carnivores (Červinka et al. 2015). We found that the stone marten was mostly influenced by agricultural and natural land cover classes, similar to what is known from other regions (Červinka et al. 2015; Santos and Santos-Reis 2010), while the other species were mostly influenced by anthropogenic land cover classes. Previous studies found that the proportion of urban areas in the landscape can actually decrease wildlife-vehicle collisions for the red fox and European badger (Gunson et al. 2011). We found increased abundance of roadkills for low proportion of urban gradient for the red fox and the European hedgehog. The red fox may generally avoid urban areas (Grilo et al. 2009), but as a generalist it may be attracted by sparsely aggregated human settlements for foraging (McCleery et al. 2014). The European hedgehog, occurring in higher densities in urban landscapes (Hubert
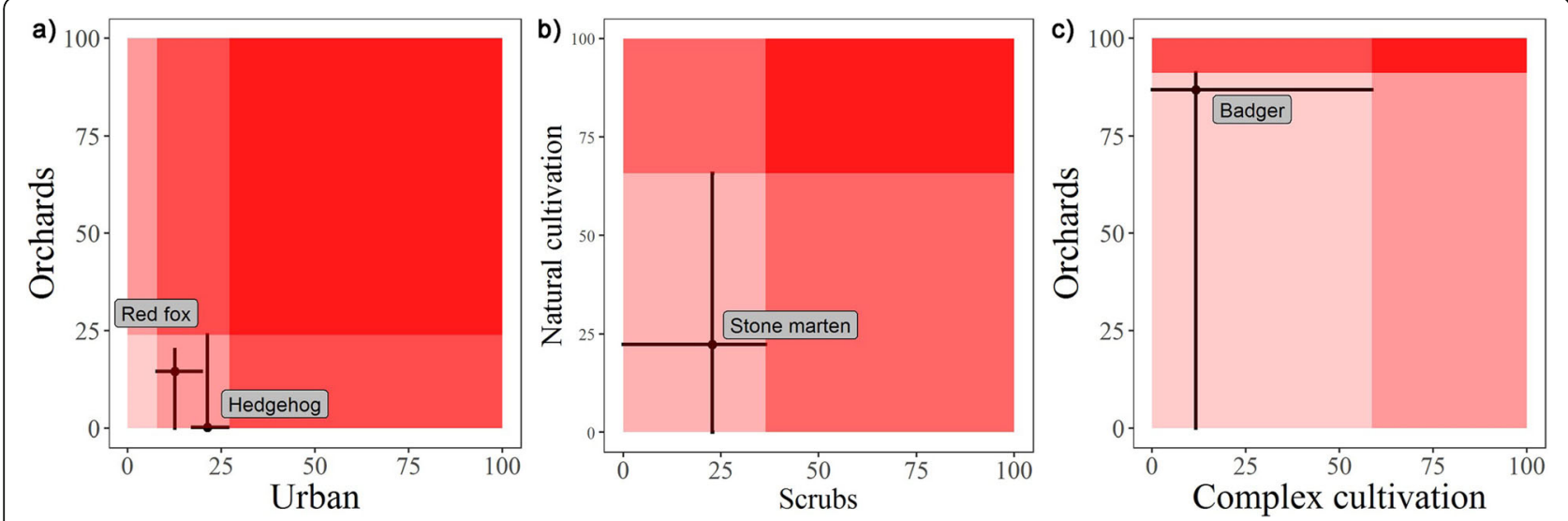

Fig. 5 Change points with 95\% confidence interval for red fox, European hedgehog, stone marten, and European badger along the corresponding land cover class gradient, resulted from the analysis including a road segment length of $1000 \mathrm{~m}$. Light-dark red shades indicate increasing risk 


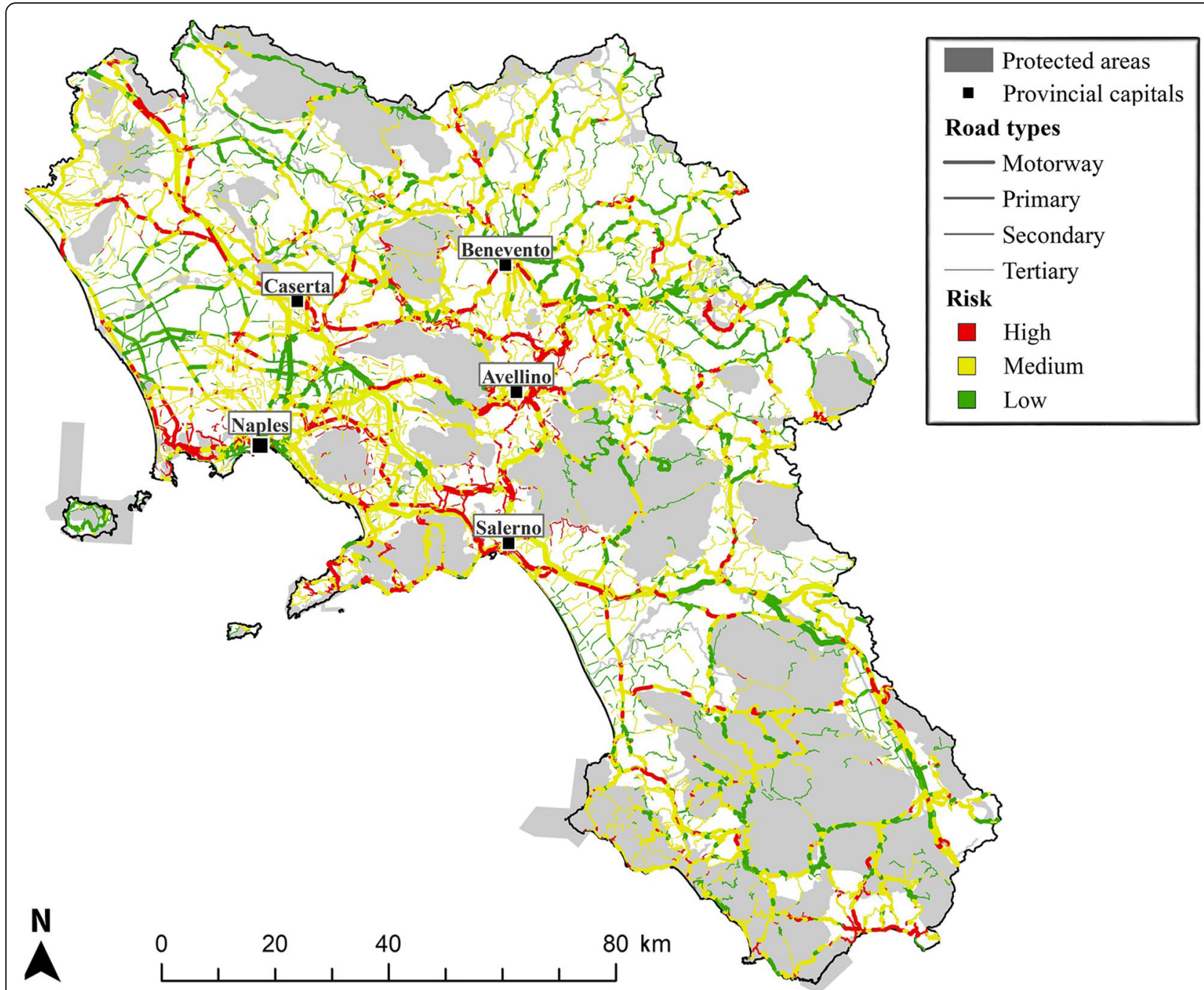

Fig. 6 Cumulative risk assessment map for wildlife-vehicle collision risk for mammal species, considering road segment length of $1000 \mathrm{~m}$

et al. 2011), also shows an increase in roadkills at moderate levels of urban cover, possibly linked with its use of roads as dispersing corridors (Patrick Doncaster et al. 2001), although roads seem to be avoided during foraging (Dowding et al. 2010). It is also known that this species may occur at higher density in food-rich landscapes such as rural landscapes (Hubert et al. 2011). Here, the European hedgehog tends to avoid areas suitable for the European badger, particularly in urbanrelated habitats (Dowding et al., 2010). The European badger is also known to occur in rural areas characterized by woody and shrubby vegetation, river valleys, and close to urban settlements, where it is more susceptible to vehicle collisions as the density of regional and local roads increases (Fabrizio et al. 2019). This is supported by our results showing an increase in roadkills along the gradients of complex cultivations and orchards. It also should be mentioned that across the geographical range of species, the use of landscapes bisected by roads can be subject to differences, depending on local characteristics, resulting in diverging roadkill drivers for different areas (Pagany 2020). On a more general level, humanrelated landscape characteristics have been found as one of the major drivers of roadkill occurrence in the Mediterranean landscapes (Grilo et al. 2009).

\section{Implication for road planning}

The results provided evidence that key spatial and temporal patterns are associated with roadkills for multiple species. Relevant implications for optimizing mitigation measures need to jointly integrate multiple species within cost-efficient conservation plans, a challenging issue poorly explored in the literature (Polak et al. 2019). Our results allowed us to develop a map of areas at potential risk of wildlife-vehicle collisions, taking into account the responses of the four main species. We 
demonstrated that citizen science can help monitor extensive areas and identify hotspots for roadkills. According to the map, major hotspots of wildlife-vehicle collisions are predicted in the surroundings of the main cities, where urban cover gradually decreases in favor of agricultural cover in the lowlands or forest in the mountain ranges. Other hotspots are along major roads in extensive agricultural landscapes, while, as previously suggested, protected areas appear to be the safest. For instance, one regional park on the outskirts of Salerno, in the Sorrento peninsula, is completely surrounded by a major road that seems to effectively isolate the protected area and decrease connectivity with the rest of the mainland. Here, we observed a high risk both inside and outside the protected area, probably due to an overcrowding effect that leads animals to seek new territories over the mainland (Matthysen 2005).

Combined with the temporal results, we are able to suggest where and when mitigation measures should be implemented. The hotspots should be subject to long-term measures such as partial fencing paired with crossing structures (Ascensão et al. 2013; Grilo et al. 2015). Fencing might be a valid mitigation measure for small mammals as well (D'Amico et al. 2015). However, maintenance of the mitigation structure such as underpasses (e.g., culverts) should also be implemented with regular cleaning activities, especially during detected highest peak of species mortality, in order to enhance their use by wildlife (Grilo et al. 2013; Villalva et al. 2013). Lower risk areas, instead, could be subject to temporary mitigation measures, such as temporary signs and seasonal speed reduction (Sullivan et al. 2004; Grilo et al. 2009; D'Amico et al. 2015). The measures should be prioritized in the surroundings of cities and protected areas, in order to favor survival and dispersal of wildlife and landscape permeability.

\section{Conclusions}

The support provided to road ecology research by citizen science is increasingly being recognized (Schwartz et al. 2020). Here, we describe the contribution of citizen science in terms of enhanced man-power and humanwildlife conflict awareness. Firstly, citizen science may act as a driving force for collecting large amounts of data in densely populated areas. However, one of the shortcoming was that many routes were oversampled by surveyors compared to other routes. This led many surveyors to send a disproportionately larger amount of data compared to others (Table S3), a common bias in the citizen science approach (Dickinson et al. 2010; Périquet et al. 2018). On the other side, studies comparing models built with citizen science data to models built with standardized data proved the reliability of a posteriori data filtering from citizen science (Robinson et al. 2018; Petrovan et al. 2020). Indeed, our results were mostly in agreement with the literature on the spatial and temporal responses of the studied species. The second limitation we found is that roadkills mostly pertained to common species, though this is a known characteristic of citizen science projects (Vercayie and Herremans 2015; Périquet et al. 2018; Petrovan et al. 2020). It is obvious that "Citizen Science" should not be considered a panacea whenever standardized protocols are needed (Schwartz et al. 2020). Some topics of road ecology, such as the study of road avoidance by wildlife (Grilo et al. 2012) or research on genetic isolation (Balkenhol and Waits 2009) can only be comprehensively carried out via long-term, standardized studies involving the support of technologically advanced instruments/protocols and qualified technicians. On the other hand, citizen science programs can increase people's interest and awareness about nature-related topics (Vercayie and Herremans 2015). Although citizens' involvement in science is increasing, the array of initiatives taken by each country may substantially differ, reflecting perhaps scientists' attitudes toward citizen science (Schwartz et al. 2020). In Italy, for instance, citizen science initiatives on road ecology are still limited (Schwartz et al. 2020), although some frameworks, such as the one detailed here, allow citizens to join the data collection with very little hindrance to their everyday activities. In addition, timely press releases and social media helped create a sense of community, a side effect that is typical of successful citizen science projects (Dickinson et al. 2012; Vercayie and Herremans 2015). The importance of such projects increases when baseline data, at the national or regional level, are lacking, as they have the potential to quickly collect data, raise citizens' awareness toward conservation problems and provide assessments for environment stewardship (Couvet et al. 2008; Dickinson et al. 2012).

\section{Supplementary Information}

The online version contains supplementary material available at https://doi. org/10.1186/s13717-020-00271-4.

Additional file 1: Table S1. Expert-based reclassification of the thirdlevel CORINE land cover classes.

Additional file 2: Table S1. Reclassification values of the new classes integrated in the analysis

Additional file 3: Table S3. Number of roadkill records sent by the surveyors/citizens involved in the project 'Via Libera'. We are deeply thankful to all of them

\section{Abbreviations}

GAM: Generalized additive models; TITAN: Threshold indicator taxa analysis

\section{Acknowledgements}

We are deeply thankful to all the citizens/surveyors that voluntarily joined the data collection effort: Aldo Crisci, Alessio Becucci, Andrea Senese, Antonio Croce, Arnaldo Iudici, Camillo Campolongo, Claudio D’Esposito, Cristina Venezia, Daniele Scinti Roger, Davide De Rosa, Enrico Tammariello, Enza Notorio, Francesca Buoninconti, Gabriele Del Gaizo, Gaspare Adinolfi, Giovanni Capobianco, Ignazio Avella, Ilaria Cammarata, Jessica Papa, Marcello Giannotti, Marco Marotti, Marilena Izzo, Michele Soprano, Michele Innangi, 
Nicola Campomorto, Ottavio Janni, Pietro Balestrieri, Salvatore Ferraro, Silvia Romano, Stefano Erbaggio, Valeria Balestrieri. We are also thankful to Mario Posillico for his useful comments on the manuscript. FV was funded by Fundação para a Ciência e a Tecnologia (SFRH/BD/122854/2016). We are thankful to Ottavio Janni for revising the language.

\section{Authors' contributions}

FV conceived the idea. FV, MB, and RB coordinated the data collection. FV and $\mathrm{MB}$ performed the data management and analysis. $\mathrm{FV}, \mathrm{MB}$, and $\mathrm{RB}$ drafted the manuscript. The authors read and approved the final manuscript.

\section{Funding}

No funding was received for this work.

\section{Availability of data and materials}

The data is available at DOI: https://urldefense.proofpoint.com/v2/url?u= http-3A_dx.doi.org_10.17632_xd6ycjkyfm.1\&d=DwICbA\&c=vh6 FgFnduejNhPPD0fl_yRaSfZy8CWbWnlf4XJhSqx8\&r=UeJ5NOk-Fhtwwow0-4 Uo0LWD73xOh6AIRqaybEDLiw0\&m=E8T1ltddB_c89_mHZ79CHuE-_OA8by3 KUIz2qthPSN8\&s=YgrrmKXDFuvRi9pYowW_7g6o8JfmXhpE4k1 wNGmkDfU\&e=

\section{Ethics approval and consent to participate}

Not applicable

\section{Consent for publication}

We confirm that people involved in the data collection confirmed their consent for publication.

\section{Competing interests}

We have no competing interest to disclose.

\section{Author details}

Mediterranean Institute for Agriculture, Environment and Development, Instituto de Investigação e Formação Avançada, Universidade de Évora, Pólo da Mitra, Ap. 94, 7006-554 Évora, Portugal. ${ }^{2}$ UBC - Unidade de Biologia da Conservação, Departamento de Biologia, Universidade de Évora, Pólo da Mitra, Ap. 94, 7002-554 Évora, Portugal. ${ }^{3}$ Associazione per la Ricerca, la Divulgazione e l'Educazione Ambientale - ARDEA, Via Ventilabro, 80126 Napoli, Italy. ${ }^{4}$ Chair of Wildlife Ecology and Management, University of Freiburg, Tennenbacher Str. 4, 79106 Freiburg, Germany. ${ }^{5}$ Stazione Zoologica Anton Dohrn, Villa Comunale 1, 80121 Naples, Italy.

\section{Received: 28 August 2020 Accepted: 14 November 2020}

Published online: 07 January 2021

\section{References}

Abu Baker MA, Reeve N, Conkey AAT et al (2017) Hedgehogs on the move: testing the effects of land use change on home range size and movement patterns of free-ranging Ethiopian hedgehogs. PLoS One 12:e0180826. https://doi.org/10.1371/journal.pone.0180826

Ascensão F, Clevenger A, Santos-Reis M et al (2013) Wildlife-vehicle collision mitigation: is partial fencing the answer? An agent-based model approach. Ecol Model 257:36-43. https://doi.org/10.1016/j.ecolmodel.2013.02.026

Baker ME, King RS (2010) A new method for detecting and interpreting biodiversity and ecological community thresholds. Methods Ecol Evol 1:2537. https://doi.org/10.1111/j.2041-210x.2009.00007x

Baker PJ, Dowding CV, Molony SE et al (2007) Activity patterns of urban red foxes (Vulpes vulpes) reduce the risk of traffic-induced mortality. Behav Ecol 18:716724. https://doi.org/10.1093/beheco/arm035

Balkenhol N, Waits LP (2009) Molecular road ecology: exploring the potential of genetics for investigating transportation impacts on wildlife. Mol Ecol 18 : 4151-4164. https://doi.org/10.1111/j.1365-294X.2009.04322.x

Benítez-López A, Alkemade R, Verweij PA (2010) The impacts of roads and other infrastructure on mammal and bird populations: a meta-analysis. Biol Conserv 143:1307-1316. https://doi.org/10.1016/j.biocon.2010.02.009

Bennett VJ (2017) Effects of road density and pattern on the conservation of species and biodiversity. Curr Landsc Ecol Rep 2:1-11. https://doi.org/10. 1007/s40823-017-0020-6
Bird TJ, Bates AE, Lefcheck JS et al (2014) Statistical solutions for error and bias in global citizen science datasets. Biol Conserv 173:144-154. https://doi.org/10. 1016/j.biocon.2013.07.037

Bissonette JA, Kassar CA, Cook $\sqcup$ (2008) Assessment of costs associated with deer-vehicle collisions: human death and injury, vehicle damage, and deer loss. Hum Wildl Conflicts 2:17-27

Carvalho F, Mira A (2011) Comparing annual vertebrate road kills over two time periods, 9 years apart: a case study in Mediterranean farmland. Eur J Wild Res 57:157-174. https://doi.org/10.1007/s10344-010-0410-0

Červinka J, Riegert J, Grill S, Šálek M (2015) Large-scale evaluation of carnivore road mortality: the effect of landscape and local scale characteristics. Mammal Res 60:233-243. https://doi.org/10.1007/s13364-015-0226-0

Coffin AW (2007) From roadkill to road ecology: a review of the ecological effects of roads. J Transp Geogr 15:396-406. https://doi.org/10.1016/j.jtrangeo.2006.11.006

Couvet $D$, Jiguet $F$, Julliard $R$ et al (2008) Enhancing citizen contributions to biodiversity science and public policy. Interdiscip Sci Rev 33:95-103. https:// doi.org/10.1179/030801808X260031

D'Amico M, Román J, de los Reyes L, Revilla E (2015) Vertebrate road-kill patterns in Mediterranean habitats: who, when and where. Biol Conserv 191:234-242. doi: https://doi.org/10.1016/j.biocon.2015.06.010

Dickinson لL, Shirk J, Bonter D et al (2012) The current state of citizen science as a tool for ecological research and public engagement. Front Ecol Environ 10: 291-297. https://doi.org/10.1890/110236

Dickinson JL, Zuckerberg B, Bonter DN (2010) Citizen science as an ecological research tool: challenges and benefits. Annu Rev Ecol Evol Syst 41:149-172. https://doi.org/10.1146/annurev-ecolsys-102209-144636

Dowding CV, Harris S, Poulton S, Baker PJ (2010) Nocturnal ranging behaviour of urban hedgehogs, Erinaceus europaeus, in relation to risk and reward. Anim Behav 80:13-21. https://doi.org/10.1016/j.anbehav.2010.04.007

Ducci D, Tranfaglia G (2008) Effects of climate change on groundwater resources in Campania (southern Italy). Geol Soc Spec Publ 288:25-38. https://doi.org/ $10.1144 /$ SP288.3

Dufrêne M, Legendre P (1997) Species assemblages and indicator species: the need for a flexible asymmetrical approach. Ecol Monogr 67:345-366. https:// doi.org/10.1890/0012-9615(1997)067[0345:SAAIST]2.0.CO;2

Dwyer RG, Carpenter-Bundhoo L, Franklin CE, Campbell HA (2016) Using citizencollected wildlife sightings to predict traffic strike hot spots for threatened species: a case study on the southern cassowary. J Appl Ecol 53:973-982. https://doi.org/10.1111/1365-2664.12635

Fabrizio M, Di Febbraro M, D'Amico M et al (2019) Habitat suitability vs landscape connectivity determining roadkill risk at a regional scale: a case study on European badger (Meles meles). Eur J Wildl Res 65:7. https://doi.org/10.1007/ s10344-018-1241-7

Forman RTT, Alexander LE (1998) Roads and their major ecological effects. Annu Rev Ecol Syst 29:207-231. https://doi.org/10.1146/annurev.ecolsys.29.1.207

Freitag A, Meyer R, Whiteman L (2016) Strategies employed by citizen science programs to increase the credibility of their data. Citiz Sci Theory Pract 1:2. https://doi.org/10.5334/cstp.6

Grilo C, Ascensão F, Santos-Reis M, Bissonette JA (2011) Do well-connected landscapes promote road-related mortality? Eur J Wildl Res 57:707-716. https://doi.org/10.1007/s10344-010-0478-6

Grilo C, Bissonette JA, Cramer PC (2013) Mitigation measures to reduce impacts on biodiversity. In: Highways: Construction, Management, and Maintenance. Nova Science Publisher, Inc., pp 73-114

Grilo C, Bissonette JA, Santos-Reis M (2009) Spatial-temporal patterns in Mediterranean carnivore road casualties: consequences for mitigation. Biol Conserv 142:301-313. https://doi.org/10.1016/j.biocon.2008.10.026

Grilo C, de Resende CT, Solar R, Bager A (2016) Do the size and shape of spatial units jeopardize the road mortality-risk factors estimates? Nat Conserv 14:813. https://doi.org/10.1016/J.NCON.2016.01.001

Grilo C, Koroleva E, Andrášik R et al (2020) Roadkill risk and population vulnerability in European birds and mammals. Front Ecol Environ:1-6. https:// doi.org/10.1002/fee.2216

Grilo C, Smith DJ, Klar N (2015) Carnivores: struggling for survival in roaded landscapes. In: van der Ree R, Smith DJ, Grilo C (eds) Handbook of Road Ecology. John Wiley \& Sons, Ltd, pp 300-312

Grilo C, Sousa J, Ascensão F et al (2012) Individual spatial responses towards roads: implications for mortality risk. PLoS One 7:1-11. https://doi.org/10. 1371/journal.pone.0043811

Gunson KE, Mountrakis G, Quackenbush $\sqcup$ (2011) Spatial wildlife-vehicle collision models: a review of current work and its application to transportation mitigation 
projects. J Environ Manage 92:1074-1082. https://doi.org/10.1016/j.jenvman.2010. 11.027

Haddad NM (2015) Corridors for people, corridors for nature. Science 350:11661167. https://doi.org/10.1126/science.aad5072

Haigh A, O'Riordan RM, Butler F (2014) Hedgehog Erinaceus europaeus mortality on Irish roads. Wildlife Biol 20:155-160. https://doi.org/10.2981/wlb.12126

Hastie TJ, Tibshirani RJ (1990) Generalized additive models. Chapman and Hall/ $\mathrm{CRC}$

Heigl F, Horvath K, Laaha G, Zaller JG (2017) Amphibian and reptile road-kills on tertiary roads in relation to landscape structure: using a citizen science approach with open-access land cover data. BMC Ecol 17:24. https://doi.org/ 10.1186/s12898-017-0134-z

Henry C, Poulle M-L, Roeder J-J (2005) Effect of sex and female reproductive status on seasonal home range size and stability in rural red foxes (Vulpes vulpes). Écoscience 12:202-209. https://doi.org/10.2980/i1195-6860-12-2-202.1

Hubert P, Julliard R, Biagianti S, Poulle ML (2011) Ecological factors driving the higher hedgehog (Erinaceus europeaus) density in an urban area compared to the adjacent rural area. Landsc Urban Plan 103:34-43. https://doi.org/10. 1016/j.landurbplan.2011.05.010

Hutchinson MF, de Hoog FR (1985) Smoothing noisy data with spline functions. Numer Math 47:99-106. https://doi.org/10.1007/BF01389878

Khattre R, Naik DN (2018) Applied multivariate statistics with SAS software.

Kowalczyk R, Zalewski A, Bogumiła J (2006) Daily movement and territory use by badgers Meles meles in Białowieża Primeval Forest, Poland. Wildlife Biol 12: 385-391. https://doi.org/10.2981/0909-6396(2006)12[385:dmatub]2.0.co;2

Langbein J, Putman R, Pokorny B (2011) Traffic collisions involving deer and other ungulates in Europe and available measures for mitigation. In: Putman R, Apollonio M, Andersen R (eds) Ungulate management in Europe. Cambridge University Press, Cambridge, pp 215-259

Laurance WF, Peletier-Jellema A, Geenen B et al (2015) Reducing the global environmental impacts of rapid infrastructure expansion. Curr Biol 25:R259R262. https://doi.org/10.1016/j.cub.2015.02.050

Matthysen E (2005) Density-dependent dispersal in birds and mammals. Ecography 28:403-416. https://doi.org/10.1111/j.0906-7590.2005.04073.x

McCleery RA, Moorman CE, Peterson MN (2014) Urban Wildlife Conservation: Theory and Practice. Springer, New York

Meijer JR, Huijbregts MAJ, Schotten KCGJ, Schipper AM (2018) Global patterns of current and future road infrastructure. Environ Res Lett 13:064006. https://doi. org/10.1088/1748-9326/aabd42

Migliozzi A, Cona F, Gennaro A et al (2010) Land-use management and changes in Campania Region (Southern Italy): examples from ten regional State Forests. In: Azevedo JC, Feliciano M, Castro J, Pinto MA (eds) Forest Landscapes and Global Change - New Frontiers in Management, Conservation and Restoration. Proceedings of the IUFRO Landscape Ecology Working Group International Conference. Instituto Politécnico de Bragança, Bragança, Portugal, Bragança, Portugal, pp 520-525

Mimet A, Clauzel C, Foltête JC (2016) Locating wildlife crossings for multispecies connectivity across linear infrastructures. Landsc Ecol 31:1955-1973. https:// doi.org/10.1007/s10980-016-0373-y

Noonan MJ, Markham A, Newman C et al (2014) Climate and the individual: inter-annual variation in the autumnal activity of the European badger (Meles meles). PLoS One 9:e83156. https://doi.org/10.1371/journal.pone.0083156

Nyhus PJ (2016) Human-wildlife conflict and coexistence. Annu Rev Environ Resour 41:143-171

Olson DD, Bissonette JA, Cramer PC et al (2014) Monitoring wildlife-vehicle collisions in the Information Age: how smartphones can improve data collection. PLoS One 9:e98613. https://doi.org/10.1371/journal.pone.0098613

Pagany R (2020) Wildlife-vehicle collisions - Influencing factors, data collection and research methods. Biol Conserv 251:108758. https://doi.org/10.1016/j. biocon.2020.108758

Patrick Doncaster C, Rondinini C, Johnson PCD (2001) Field test for environmental correlates of dispersal in hedgehogs Erinaceus europaeus. J Anim Ecol 70:33-46. https://doi.org/10.1046/j.1365-2656.2001.00471.x

Périquet S, Roxburgh L, le Roux A, Collinson WJ (2018) Testing the value of citizen science for roadkill studies: a case study from South Africa. Front Ecol Evol 6:15. https://doi.org/10.3389/fevo.2018.00015

Petrovan SO, Vale CG, Sillero N (2020) Using citizen science in road surveys for large-scale amphibian monitoring: are biased data representative for species distribution? Biodivers Conserv 29:1767-1781. https://doi.org/10.1007/s10531020-01956-0
Polak T, Nicholson E, Grilo C et al (2019) Optimal planning to mitigate the impacts of roads on multiple species. J Appl Ecol 56:201-213. https://doi.org/ 10.1111/1365-2664.13258

Posillico M, Serafini P, Lovari S (1995) Activity patterns of the stone marten Martes foina Erxleben, 1777, in relation to some environmental factors. Hystrix 7:7997. https://doi.org/10.4404/hystrix-7.1-2-4056

Raichev E (2014) Factors influencing the mortality of stone marten (Martes foina) in road accidents. Trakia J Sci 12:89-93

Ramsay JO, Silverman BW (2005) Functional data analysis. Springer-Verlag, New York, NY

Robinson OJ, Ruiz-Gutierrez V, Fink D (2018) Correcting for bias in distribution modelling for rare species using citizen science data. Divers Distrib 24:460472. https://doi.org/10.1111/ddi.12698

Rogers LM, Delahay R, Cheeseman CL et al (1998) Movement of badgers (Meles meles) in a high-density population: individual, population and disease effects. Proc R Soc B Biol Sci 265:1269-1276. https://doi.org/10.1098/rspb. 1998.0429

Rosalino LM, Macdonald DW, Santos-Reis M (2004) Spatial structure and landcover use in a low-density Mediterranean population of Eurasian badgers. Can J Zool 82:1493-1502. https://doi.org/10.1139/Z04-130

Santos MJ, Santos-Reis M (2010) Stone marten (Martes foina) habitat in a Mediterranean ecosystem: effects of scale, sex, and interspecific interactions. Eur J Wildl Res 56:275-286. https://doi.org/10.1007/s10344-009-0317-9

Santos RAL, Santos SM, Santos-Reis M et al (2016) Carcass persistence and detectability: reducing the uncertainty surrounding wildlife-vehicle collision surveys. PLoS One 11:e0165608. https://doi.org/10.1371/journal.pone.0165608

Santos SM, Carvalho F, Mira A (2011) How long do the dead survive on the road? Carcass persistence probability and implications for road-kill monitoring surveys. PLoS One 6:e25383. https://doi.org/10.1371/journal.pone.0025383

Saunders SC, Mislivets MR, Chen J, Cleland DT (2002) Effects of roads on landscape structure within nested ecological units of the Northern Great Lakes Region, USA. Biol Conserv 103:209-225. https://doi.org/10.1016/S00063207(01)00130-6

Schwartz ALW, Shilling FM, Perkins SE (2020) The value of monitoring wildlife roadkill. Eur J Wildl Res 66. https://doi.org/10.1007/s10344-019-1357-4

Spanowicz AG, Teixeira FZ, Jaeger JAG (2020) An adaptive plan for prioritizing road sections for fencing to reduce animal mortality. Conserv Biol 34:12101220. https://doi.org/10.1111/cobi.13502

Sullivan TL, Williams AF, Messmer TA et al (2004) Effectiveness of temporary warning signs in reducing deer-vehicle collisions during mule deer migrations. Wildl Soc Bull 32:907-915. https://doi.org/10.2193/00917648(2004)032[0907:eotwsi]2.0.co;2

Tanner AL, Leroux SJ, Saunders PW (2017) Road characteristics best predict the probability of vehicle collisions with a non-native ungulate. Ecoscience 24:111. https://doi.org/10.1080/11956860.2017.1292100

Thompson AM, Brown JC, Kay JW, Titterington DM (1991) A study of methods of choosing the smoothing parameter in image restoration by regularization. IEEE Trans Pattern Anal Mach Intell 13:326-339

Travaini A, Aldama JJ, Laffitte R, Delibes M (1993) Home range and activity patterns of red fox Vulpes vulpes breeding females. Acta Theriol 38:427-434

Valerio F, Carvalho F, Barbosa AM et al (2019) Accounting for connectivity uncertainties in predicting roadkills: a comparative approach between path selection functions and habitat suitability models. Environ Manage 64:329343. https://doi.org/10.1007/s00267-019-01191-6

van der Grift EA, van der Ree R (2015) Guidelines for evaluating use of wildlife crossing structures. In: Handbook of Road Ecology. John Wiley \& Sons, Ltd, Chichester, UK, pp 119-128

van der Ree R, Jaeger JAG, van der Grift EA, Clevenger AP (2011) Effects of roads and traffic on wildlife populations and landscape function: road ecology is moving toward larger scales. Ecol Soc 16. https://doi.org/10.5751/ES-03982160148

van der Ree R, Smith DJ, Grilo C (2015) The ecological effects of linear infrastructure and traffic. In: Handbook of Road Ecology. John Wiley \& Sons, Ltd, Chichester, UK, pp 1-9

Vantieghem P, Maes D, Kaiser A, Merckx T (2017) Quality of citizen science data and its consequences for the conservation of skipper butterflies (Hesperiidae) in Flanders (northern Belgium). J Insect Conserv 21:451-463. https://doi.org/ 10.1007/s10841-016-9924-4

Vercayie D, Herremans M (2015) Citizen science and smartphones take roadkill monitoring to the next level. Nat Conserv 11:29-40. https://doi.org/10.3897/ natureconservation.11.4439 
Villalva P, Reto D, Santos-Reis M et al (2013) Do dry ledges reduce the barrier effect of roads? Ecol Eng 57:143-148. https://doi.org/10.1016/j.ecoleng.2013. 04.005

Wahba G (1990) Spline models for observational data. Society for Industrial and Applied Mathematics

Xiang D (2001) Fitting generalized additive models with the GAM procedure. SAS Global Forum 2008. Cary, NC, USA

Russo LF, Barrientos R, Fabrizio M, Di Febbraro M, Loy A (2020) Prioritizing roadkill mitigation areas: a spatially explicit national-scale model for an elusive carnivore. Divers Distrib 26:1093-1103

\section{Publisher's Note}

Springer Nature remains neutral with regard to jurisdictional claims in published maps and institutional affiliations.

\section{Submit your manuscript to a SpringerOpen ${ }^{\circ}$ journal and benefit from:}

- Convenient online submission

- Rigorous peer review

- Open access: articles freely available online

- High visibility within the field

- Retaining the copyright to your article

Submit your next manuscript at $\boldsymbol{\nabla}$ springeropen.com 